\title{
Regulatory T Cell Therapy for Ischemic Stroke: how far from Clinical Translation?
}

\author{
Yuguo $\mathrm{Xia}^{1} \cdot \mathrm{Wei} \mathrm{Cai}^{1} \cdot$ Angus W. Thomson ${ }^{2} \cdot \mathrm{Xiaoming} \mathrm{Hu}^{1}$
}

Received: 8 June 2016 / Accepted: 10 June 2016 / Published online: 16 June 2016

(C) Springer Science+Business Media New York 2016

Ischemic stroke remains a leading cause of death and disability worldwide. The effective treatment for stroke is very limited [1-3]. Accumulating evidence implicates inflammation and immune responses in the pathophysiology of stroke as well as other brain injuries [4-7]. For ischemic stroke, the sudden occlusion of a cerebral vessel leads to acute ischemic damage, which is followed by immediate activation of local immune cells and prompt mobilization of peripheral immune cells. Initially, innate immune cells function to restrict brain damage by clearing cell debris and neutralizing neurotoxins. However, consequent amplification of the adaptive immune response propels the progress of ischemic brain injury. Immunomodulation (immunotherapy) therefore has become a promising concept for stroke treatment [8-13].

Recent research findings have shown that regulatory immune cells, including regulatory $\mathrm{T}$ cells (Treg) [14-16] and regulatory B cells [17-19], may serve as endogenous modulators to control immune responses in the injured brain. Particular interest has arisen regarding the therapeutic potential of Treg in ischemic stroke. Treg are a rare, specialized $\mathrm{T}$ lymphocytes characterized by co-expression of the cell surface markers CD4 and CD25 (IL-2Ra) and by expression of the transcription factor forkhead box p3 (Foxp3). Treg can be classified into two subpopulations: naturally-occurring, thymus-derived Treg (nTreg), and induced Treg (iTreg) that are derived from

Xiaoming $\mathrm{Hu}$

hux2@upmc.edu

1 Department of Neurology, University of Pittsburgh School of Medicine, 200 Lothrop Street, SBST 506, Pittsburgh, PA 15213, USA

2 Starzl Transplantation Institute, University of Pittsburgh School of Medicine, Pittsburgh, PA 15213, USA
$\mathrm{CD} 4^{+} \mathrm{CD} 25^{-} \mathrm{T}$ cells in secondary lymphoid organs in response to antigen exposure. The primary function of Treg is to suppress the proliferation and function of other immune cells, especially effector $\mathrm{T}$ lymphocytes and to maintain immune homeostasis. The protective effect of Treg in ischemic stroke was first documented by Liesz et al. [16]. They reported that Treg depletion using a CD25-specific antibody resulted in enhanced tissue loss and worsened neurological functions 7 days after cerebral ischemia. Later studies using a genetic mouse model of inducible Treg depletion, however, led to controversial results, showing either no effect [20] or even a detrimental effect [21] of Treg in the stroke model. Such a striking discrepancy may be attributed to the different approaches used to deplete Treg, the dynamic nature of post-stroke immunity, and the variance in stroke severity $[22,23]$.

Despite these controversial results of cell depletion studies, interest in Treg therapy of stroke has piqued, initially due to a series of encouraging reports of early Treg-based clinical trials in autoimmune disease and transplantation [24-30]. In addition, clinical studies have revealed a dramatic decrease in the number of circulating Treg soon after stroke onset, which provides a rationale for Treg augmentation in stroke patients [31-33]. The results from animal models of stroke further suggest that boosting the number and/or function of Treg could protect against ischemic brain injury. A recent meta-analysis of current preclinical studies indicates an overall neuroprotective effect of Treg-targeted therapies in models of stroke. Adoptive transfer of 2 million purified polyclonal Treg, which is the most straightforward approach to Treg augmentation, has been shown to provide acute protection and to promote long-term recovery in a mouse model of stroke [14, 15]. Impressively, the therapeutic window of Treg administration can be delayed until $24 \mathrm{~h}$ after the onset of ischemia, making it applicable to humans who may not be treated in the clinic for many hours after symptom onset. The Treg-enabled neuroprotection may involve the 
interplay of multiple cellular and molecular mechanisms, including restricting excessive central nervous system (CNS) and peripheral immune responses, ameliorating acute blood brain barrier damage, and promoting neural stem cell proliferation for brain repair [14-16]. Intriguingly, the early protective effect of adoptively-transferred Treg does not require passage across the blood brain barrier. Rather, these cells may provide CNS protection by ameliorating the deleterious activities of peripheral immune cells $[14,34]$. The Treg may infiltrate into the ischemic brain 5 days after stroke and exert further immune modulation or restorative effects in the brain. Collectively, these preclinical results fuel hope for the development of Treg therapy into a clinically feasible treatment for stroke.

The clinical application of Treg as a cell therapy requires the isolation and purification of sufficient numbers of cells from the blood. However, Treg represent only $5-10 \%$ of normal circulating T cells $[35,36]$. Such a low frequency, as well as the anergic property of Treg apparently restricts their clinical utility as a cell therapy for stroke. This limitation, promisingly, has been overcome with the development of approaches for ex vivo or in vivo Treg expansion. Several methods have been developed to successfully expand Treg ex vivo. When crosslinked with anti-CD3 and anti-CD28 antibodies in the presence of exogenous IL-2, Treg expand robustly ex vivo, while retaining their phenotype and suppressive activities [37, 38]. The addition of the serine-threonine protein kinase inhibitor rapamycin prevents the acquisition of $\mathrm{T}$ effector cell functions and allows selective expansion of Treg, even if they are not absolutely pure initially [39, 40]. Significantly, repetitive stimulation with good manufacturing practice (GMP)-licensed artificial antigen-presenting cells (aAPC) in the presence of anti-CD3/CD28 Ab, IL-2, and rapamycin can greatly (about 3000 -fold after a single restimulation and 50 million-fold after four rounds of re-stimulation) expand the number of human peripheral blood-derived nTreg with retention of Treg signatures [41]. Such massive ex vivo expansion dramatically advances the potential clinical utility of Treg therapy. Accumulating evidence from bench-tobedside studies demonstrates the safety and preliminary evidence of efficacy of ex vivo-expanded Treg in autoimmune disease (type-1 diabetes) [28], organ transplantation [30], and graft-versus-host disease (GVHD) following hematopoietic stem cell transplantation $[25,26]$.

It is certainly an intriguing idea to expand autologous Treg for stroke treatment. However, the ex vivo expansion of Tres usually takes several weeks to achieve a target number of cells. Considering the abrupt onset and fast progress of most cases of stroke, autologous Treg might not be applicable for stroke patients. In this regard, the non-autologous expansion of nTreg derived from umbilical cord blood (UCB) provides a possibility for advance preparation of large number of third party Treg that could be promising for clinical translation. Indeed, it has been reported that nTreg can be purified more readily from UCB than from peripheral blood due to the relative paucity of $\mathrm{CD} 25^{+}$non-Treg in UCB [42]. Murine studies have shown that adoptive transfer of ex vivo-expanded UCBderived Treg could ameliorate GVHD [43, 44]. One clinical trial has confirmed the safety and potential efficacy of ex vivoexpanded UCB Treg to prevent acute GVHD [25]. The potential clinical application of third-party UCB-derived Treg in stroke patients merits further investigation.

An alternative approach to increase the number of therapeutic Treg is to expand Treg in vivo using different stimulants. For example, complexes of IL-2 and a specific anti-IL-2 $\mathrm{Ab}$ JES6-1 can induce selective expansion of Treg by blocking the binding site on IL-2 that is needed for the expansion of other T cells [45]. Injection of IL-2/IL-2Ab complexes for a short period has been shown to expand the number of highly-activated Treg in multiple organs $[46,47]$. In vivoexpanded Treg are effective in treating experimental autoimmune disease and reducing transplant rejection [46, 47]. Another promising method for in vivo Treg expansion is the use of monoclonal Ab to DR3 (aDR3). A single dose of aDR3 in mice selectively expands functional Treg in vivo and significantly ameliorates acute GVHD [48]. In addition, pretreatment with aDR3 for 4 days led to nTreg expansion in recipient mice and prolonged graft survival after allogeneic heart transplantation [49]. Different from IL-2 complexes or aDR3, Flt3 ligand (Flt3L) represents an indirect but effective strategy for in vivo Treg expansion. Flt3L is a hematopoietic growth factor that stimulates the development of conventional myeloid dendritic cells (DCs) and non-conventional plasmacytoid DCs [50]. Both preclinical and clinical studies have revealed that Flt3L administration greatly elevates peripheral Treg cell numbers via expansion of DCs [51, 52]. Furthermore, Flt3L and rapamycin can synergistically induce antigen-specific Treg via selective expansion of plasmacytoid DCs [53]. All of these approaches for in vivo Treg expansion, although still in the initial stages of preclinical exploration, may represent promising agents for immunoregulatory therapies in a variety of clinical settings, including ischemic stroke.

Despite promising evidence of the effectiveness of Tregtargeted immunotherapies in animal models of stroke, there are still concerns about the potential risks of clinical translation of Treg therapy. The first concern is that augmenting Treg could exacerbate post-stroke immunosuppression and therefore increase the risk of infectious comorbidities or cancer. This concern, however, has been partially addressed by animal studies showing that adoptive Treg therapy does not exacerbate post-stroke immunosuppression [14, 54]. Indeed, Treg therapy helps to preserve the lymphocytic populations in blood and spleen after stroke and reduces the risk of poststroke infection $[14,54]$. Nevertheless, the effects of Treg therapy on post-stroke immunity in patients still need to be carefully evaluated. Another justified concern is that the expanded Treg may convert to effector Th17 cells in an 
inflammatory milieu, especially in the presence of IL-6. It is reported that when some factors, such as rapamycin, transforming growth factor (TGF)- $\beta$, and all trans retinoic acid, are added into the cocktail for Treg expansion, they can enhance the suppressive function of expanded Treg and prevent their conversion into Th17 cells $[55,56]$. However, the effectiveness of these agents in the expansion of human Treg awaits further evaluation. In addition, for therapies involving in vivo Treg expansion, the potential toxicities of Treg stimulants need to be carefully assessed.

It is becoming increasingly clear that the modulation of post-stroke immune responses will be an effective strategy to restrict ischemic brain injury and promote brain recovery [57]. More and more preclinical studies validate Treg as a promising candidate for immune cell therapy for stroke. With the development of techniques that enable Treg expansion while maintaining their function and stability, the road to effective application of Treg to clinical setting of stroke becomes broader.

In spite of these unprecedented advances, some concerns and challenges remain. For example, for the treatment of CNS diseases like stroke, there is a requirement for ex vivo-expanded Treg to express appropriate homing (chemokine) receptors so that they can preferentially traffic to the injured brain versus other lymphoid or inflamed tissues. Approaches need to be established to confirm the homing and persistence of adoptivelytransferred Treg in the human brain. In addition, the therapeutic dose of polyclonal Treg in human stroke is unclear. Moreover, post stroke immune response changes occur dynamically during the pathological process and differ with factors such as age, gender, or comorbidities [58-60]. Therefore, we envision that Tregtargeted therapies, like immunotherapies of cancer, need to be personalized according to the patients' immune condition and adjusted accordingly during the course of stroke recovery. A collaborative effort between basic neuroscientists, immunologists, and neurologists will be required for the ultimate successful bench-to-bedside translation of Treg therapy for stroke treatment.

\section{Compliance with Ethical Standards}

Funding Xiaoming Hu was supported by the NIH/National Institute of neurological disorders and stroke (NINDS) grants NS094573 and NS092618.

Conflict of Interest The authors declare that they have no conflict of interest.

Ethical Approval This article does not contain any studies with human participants or animals performed by any of the authors.

\section{References}

1. Romano JG, Sacco RL. Decade in review-stroke: progress in acute ischaemic stroke treatment and prevention. Nat Rev Neurosci. 2015;11(11):619-21. doi:10.1038/nrneurol.2015.199.

2. O'Bryant Z, Vann KT, Xiong ZG. Translational strategies for neuroprotection in ischemic stroke-focusing on acid-sensing ion channel 1a. Transl Stroke Res. 2014;5(1):59-68. doi:10.1007 /s12975-013-0319-5.

3. Lapchak PA. A cost-effective rabbit embolic stroke bioassay: insight into the development of acute ischemic stroke therapy. Transl Stroke Res. 2015;6(2):99-103. doi:10.1007/s12975-015-0386-x.

4. Seifert HA, Pennypacker KR. Molecular and cellular immune responses to ischemic brain injury. Transl Stroke Res. 2014;5(5):54353. doi:10.1007/s12975-014-0349-7.

5. An C, Shi Y, Li P, Hu X, Gan Y, Stetler RA, et al. Molecular dialogs between the ischemic brain and the peripheral immune system: dualistic roles in injury and repair. Prog Neurobiol. 2014;115:624. doi:10.1016/j.pneurobio.2013.12.002.

6. Chen S, Yang Q, Chen G, Zhang JH. An update on inflammation in the acute phase of intracerebral hemorrhage. Transl Stroke Res. 2015;6(1):4-8. doi:10.1007/s12975-014-0384-4.

7. Hosaka K, Hoh BL. Inflammation and cerebral aneurysms. Transl Stroke Res. 2014;5(2):190-8. doi:10.1007/s12975-013-0313-y.

8. Pennypacker KR. Targeting the peripheral inflammatory response to stroke: role of the spleen. Transl Stroke Res. 2014;5(6):635-7. doi:10.1007/s12975-014-0372-8.

9. Benakis C, Brea D, Caballero S, Faraco G, Moore J, Murphy M, et al. Commensal microbiota affects ischemic stroke outcome by regulating intestinal gammadelta T cells. Nat Med. 2016;22(5):51623. doi:10.1038/nm.4068.

10. Hu X, Leak RK, Shi Y, Suenaga J, Gao Y, Zheng P, et al. Microglial and macrophage polarization-new prospects for brain repair. Nat Rev Neurosci. 2015;11(1):56-64. doi:10.1038/nrneurol.2014.207.

11. Zhu W, Casper A, Libal NL, Murphy SJ, Bodhankar S, Offner H, et al. Preclinical evaluation of recombinant $\mathrm{T}$ cell receptor ligand RTL1000 as a therapeutic agent in ischemic stroke. Transl Stroke Res. 2015;6(1):60-8. doi:10.1007/s12975-014-0373-7.

12. Zhu W, Libal NL, Casper A, Bodhankar S, Offner H, Alkayed NJ. Recombinant $\mathrm{T}$ cell receptor ligand treatment improves neurological outcome in the presence of tissue plasminogen activator in experimental ischemic stroke. Transl Stroke Res. 2014;5(5):612-7. doi:10.1007/s12975-014-0348-8.

13. Pan J, Palmateer J, Schallert T, Hart M, Pandya A, Vandenbark AA, et al. Novel humanized recombinant $T$ cell receptor ligands protect the female brain after experimental stroke. Transl Stroke Res. 2014;5(5):577-85. doi:10.1007/s12975-014-0345-y.

14. Li P Gan Y, Sun BL, Zhang F, B Lu, Y Gao, W Liang, AW Thomson, J Chen and $\mathrm{X}$ Hu. Adoptive regulatory T cell therapy protects against cerebral ischemia. Ann Neurol. 2013;74(3):45871. doi:10.1002/ana.23815.

15. Wang J, Xie L, Yang C, Ren C, Zhou K, Wang B, et al. Activated regulatory $\mathrm{T}$ cell regulates neural stem cell proliferation in the subventricular zone of normal and ischemic mouse brain through interleukin 10. Front Cell Neurosci. 2015;9:361. doi:10.3389 /fncel.2015.00361.

16. Liesz A, Suri-Payer E, Veltkamp C, Doerr H, Sommer C, Rivest S, et al. Regulatory T cells are key cerebroprotective immunomodulators in acute experimental stroke. Nat Med. 2009;15(2):192-9.

17. Ren X, Akiyoshi K, Dziennis S, Vandenbark AA, Herson PS, Hurn PD, et al. Regulatory B cells limit CNS inflammation and neurologic deficits in murine experimental stroke. J Neurosci: Off J Soc Neurosci. 2011;31(23):8556-63. doi:10.1523/JNEUROSCI.1623-11.2011. 
18. Bodhankar S, Chen Y, Vandenbark AA, Murphy SJ, Offner H. Treatment of experimental stroke with IL-10-producing B-cells reduces infarct size and peripheral and CNS inflammation in wildtype B-cell-sufficient mice. Metab Brain Dis. 2014;29(1):59-73. doi:10.1007/s11011-013-9474-3.

19. Offner H, Hurn PD. A novel hypothesis: regulatory B lymphocytes shape outcome from experimental stroke. Transl Stroke Res. 2012;3(3):324-30. doi:10.1007/s12975-012-0187-4

20. Ren X, Akiyoshi K, Vandenbark AA, Hurn PD, Offner H. CD4 + FoxP3 + regulatory T-cells in cerebral ischemic stroke. Metab Brain Dis. 2011;26(1):87-90. doi:10.1007/s11011-010-9226-6.

21. Kleinschnitz C, Kraft P, Dreykluft A, Hagedorn I, Gobel K, Schuhmann MK, et al. Regulatory $\mathrm{T}$ cells are strong promoters of acute ischemic stroke in mice by inducing dysfunction of the cerebral microvasculature. Blood. 2013;121(4):679-91. doi:10.1182 /blood-2012-04-426734.

22. Liesz A, Kleinschnitz C, Regulatory T. Cells in post-stroke immune homeostasis. Transl Stroke Res. 2016. doi:10.1007/s12975-016-0465-7.

23. Liesz A, Hu X, Kleinschnitz C, Offner H. Functional role of regulatory lymphocytes in stroke: facts and controversies. Stroke J Cereb Circ. 2015;46(5):1422-30. doi:10.1161/STROKEAHA.114.008608.

24. Theil A, Tuve S, Oelschlagel U, Maiwald A, Dohler D, Ossmann $\mathrm{D}$, et al. Adoptive transfer of allogeneic regulatory $\mathrm{T}$ cells into patients with chronic graft-versus-host disease. Cytotherapy. 2015;17(4):473-86. doi:10.1016/j.jcyt.2014.11.005.

25. Brunstein CG, Miller JS, Cao Q, McKenna DH, Hippen KL, Curtsinger J, et al. Infusion of ex vivo expanded T regulatory cells in adults transplanted with umbilical cord blood: safety profile and detection kinetics. Blood. 2011;117(3):1061-70. doi:10.1182 /blood-2010-07-293795.

26. Trzonkowski P, Bieniaszewska M, Juscinska J, Dobyszuk A, Krzystyniak A, Marek N, et al. First-in-man clinical results of the treatment of patients with graft versus host disease with human ex vivo expanded CD4 + CD25 + CD127- T regulatory cells. Clin Immunol. 2009;133(1):22-6. doi:10.1016/j.clim.2009.06.001.

27. Di Ianni M, Falzetti F, Carotti A, Terenzi A, Castellino F, Bonifacio $\mathrm{E}$, et al. Tregs prevent GVHD and promote immune reconstitution in HLA-haploidentical transplantation. Blood. 2011;117(14):39218. doi:10.1182/blood-2010-10-311894.

28. Marek-Trzonkowska N, Mysliwiec M, Dobyszuk A, Grabowska M, Techmanska I, Juscinska J, et al. Administration of CD4 + CD25highCD127- regulatory $\mathrm{T}$ cells preserves beta-cell function in type 1 diabetes in children. Diabetes Care. 2012;35(9):181720. doi:10.2337/dc12-0038.

29. Bluestone JA, Buckner JH, Fitch M, Gitelman SE, Gupta S, Hellerstein MK et al. Type 1 diabetes immunotherapy using polyclonal regulatory $\mathrm{T}$ cells. Science translational medicine. 2015;7(315):315ra189. doi:10.1126/scitranslmed.aad4134.

30. Todo S, Yamashita K, Goto R, Zaitsu M, Nagatsu A, Oura T, et al. A pilot study of operational tolerance with a regulatory $\mathrm{T}$ cell-based cell therapy in living donor liver transplantation. Hepatology. 2016. doi:10.1002/hep.28459.

31. Yan J, Greer JM, Etherington K, Cadigan GP, Cavanagh H, Henderson RD, et al. Immune activation in the peripheral blood of patients with acute ischemic stroke. J Neuroimmunol. 2009;206(1-2):112-7.

32. Urra X, Cervera A, Villamor N, Planas AM, Chamorro A. Harms and benefits of lymphocyte subpopulations in patients with acute stroke. Neuroscience. 2009;158(3):1174-83.

33. Ishibashi S, Maric D, Mou Y, Ohtani R, Ruetzler C, Hallenbeck JM. Mucosal tolerance to E-selectin promotes the survival of newly generated neuroblasts via regulatory T-cell induction after stroke in spontaneously hypertensive rats. J Cereb Blood Flow Metab. 2009;29(3):606-20.

34. Li P, Mao L, Liu X, Gan Y, Zheng J, Thomson AW, et al. Essential role of program death 1 -ligand 1 in regulatory T-cell-afforded protection against blood-brain barrier damage after stroke. Stroke J Cereb Circ. 2014;45(3):857-64. doi:10.1161 /STROKEAHA.113.004100.

35. Battaglia M, Stabilini A, Migliavacca B, Horejs-Hoeck J, Kaupper T, Roncarolo MG. Rapamycin promotes expansion of functional CD4 + CD25 + FOXP3 + regulatory T cells of both healthy subjects and type 1 diabetic patients. J Immunol. 2006;177(12):8338-47.

36. Trzonkowski P, Szarynska M, Mysliwska J, Mysliwski A. Ex vivo expansion of $\mathrm{CD} 4(+) \mathrm{CD} 25(+) \mathrm{T}$ regulatory cells for immunosuppressive therapy. Cytometry A: J Int Soc Anal Cytol. 2009;75(3): 175-88. doi:10.1002/cyto.a.20659.

37. Tang Q, Henriksen KJ, Bi M, Finger EB, Szot G, Ye J, et al. In vitro-expanded antigen-specific regulatory $\mathrm{T}$ cells suppress autoimmune diabetes. J Exp Med. 2004;199(11):1455-65.

38. Golshayan D, Jiang S, Tsang J, Garin MI, Mottet C, Lechler RI. In vitro-expanded donor alloantigen-specific $\mathrm{CD} 4+\mathrm{CD} 25+$ regulatory $\mathrm{T}$ cells promote experimental transplantation tolerance. Blood. 2007;109(2):827-35.

39. Rossetti M, Spreafico R, Saidin S, Chua C, Moshref M, Leong JY, et al. Ex vivo-expanded but not in vitro-induced human regulatory $\mathrm{T}$ cells are candidates for cell therapy in autoimmune diseases thanks to stable demethylation of the FOXP3 regulatory T cellspecific demethylated region. J Immunol. 2015;194(1):113-24. doi:10.4049/jimmunol.1401145.

40. Zhang H, Guo H, Lu L, Zahorchak AF, Wiseman RW, Raimondi G, et al. Sequential monitoring and stability of ex vivo-expanded autologous and nonautologous regulatory T cells following infusion in nonhuman primates. Am J Transplant. 2015;15(5):1253-66. doi:10.1111/ajt.13113.

41. Hippen KL, Merkel SC, Schirm DK, Sieben CM, Sumstad D, Kadidlo DM, et al. Massive ex vivo expansion of human natural regulatory $\mathrm{T}$ cells (T(regs)) with minimal loss of in vivo functional activity. Sci Transl Med. 2011;3(83):83ra41. doi:10.1126 /scitranslmed.3001809.

42. Hippen KL, Harker-Murray P, Porter SB, Merkel SC, Londer A, Taylor DK, et al. Umbilical cord blood regulatory T-cell expansion and functional effects of tumor necrosis factor receptor family members OX40 and 4-1BB expressed on artificial antigenpresenting cells. Blood. 2008;112(7):2847-57. doi:10.1182/blood2008-01-132951.

43. Parmar S, Liu X, Tung SS, Robinson SN, Rodriguez G, Cooper LJ, et al. Third-party umbilical cord blood-derived regulatory $\mathrm{T}$ cells prevent xenogenic graft-versus-host disease. Cytotherapy. 2014;16(1):90-100. doi:10.1016/j.jcyt.2013.07.009.

44. Yang J, Fan H, Hao J, Ren Y, Chen L, Li G, et al. Amelioration of acute graft-versus-host disease by adoptive transfer of ex vivo expanded human cord blood CD4 + CD25+ forkhead box protein $3+$ regulatory $\mathrm{T}$ cells is associated with the polarization of Treg/Th17 balance in a mouse model. Transfusion. 2012;52(6):1333-47. doi:10.1111/j.1537-2995.2011.03448.x.

45. Shevach EM. Application of IL-2 therapy to target T regulatory cell function. Trends Immunol. 2012;33(12):626-32. doi:10.1016/j. it.2012.07.007.

46. Webster KE, Walters S, Kohler RE, Mrkvan T, Boyman O, Surh $\mathrm{CD}$, et al. In vivo expansion of $\mathrm{T}$ reg cells with IL-2-mAb complexes: induction of resistance to EAE and long-term acceptance of islet allografts without immunosuppression. J Exp Med. 2009;206(4):751-60. doi:10.1084/jem.20082824.

47. Koreth J, Matsuoka K, Kim HT, McDonough SM, Bindra B, Alyea 3rd EP, et al. Interleukin-2 and regulatory T cells in graft-versushost disease. N Engl J Med. 2011;365(22):2055-66. doi:10.1056 /NEJMoa1108188.

48. Kim BS, Nishikii H, Baker J, Pierini A, Schneidawind D, Pan Y, et al. Treatment with agonistic DR3 antibody results in expansion of donor Tregs and reduced graft-versus-host disease. Blood. 2015;126(4):546-57. doi:10.1182/blood-2015-04-637587. 
49. Wolf D, Schreiber TH, Tryphonopoulos P, Li S, Tzakis AG, Ruiz P, et al. Tregs expanded in vivo by TNFRSF 25 agonists promote cardiac allograft survival. Transplantation. 2012;94(6):569-74. doi:10.1097/TP.0b013e318264d3ef.

50. Waskow C, Liu K, Darrasse-Jeze G, Guermonprez P, Ginhoux F, Merad M, et al. The receptor tyrosine kinase Flt3 is required for dendritic cell development in peripheral lymphoid tissues. Nat Immunol. 2008;9(6):676-83. doi:10.1038/ni.1615.

51. Klein O, Ebert LM, Zanker D, Woods K, Tan BS, Fucikova J, et al. Flt3 ligand expands CD4+ FoxP3+ regulatory T cells in human subjects. Eur J Immunol. 2013;43(2):533-9. doi:10.1002 /eji.201242603.

52. Swee LK, Bosco N, Malissen B, Ceredig R, Rolink A. Expansion of peripheral naturally occurring $\mathrm{T}$ regulatory cells by Fms-like tyrosine kinase 3 ligand treatment. Blood. 2009;113(25):6277-87. doi:10.1182/blood-2008-06-161026.

53. Biswas M, Sarkar D, Kumar SR, Nayak S, Rogers GL, Markusic DM, et al. Synergy between rapamycin and FLT3 ligand enhances plasmacytoid dendritic cell-dependent induction of CD4 + CD25 + FoxP3+ Treg. Blood. 2015;125(19):2937-47. doi:10.1182/blood2014-09-599266.

54. Li P, Mao L, Zhou G, Leak RK, Sun BL, Chen J, et al. Adoptive regulatory T-cell therapy preserves systemic immune homeostasis after cerebral ischemia. Stroke. 2013;44(12):3509-15. doi:10.1161 /STROKEAHA.113.002637.
55. Zheng SG, Wang J, Horwitz DA. Cutting edge: Foxp3 + CD4 + $\mathrm{CD} 25+$ regulatory $\mathrm{T}$ cells induced by IL-2 and TGF-beta are resistant to Th17 conversion by IL-6. J Immunol. 2008;180(11):7112-6.

56. Golovina TN, Mikheeva T, Brusko TM, Blazar BR, Bluestone JA, Riley JL. Retinoic acid and rapamycin differentially affect and synergistically promote the ex vivo expansion of natural human $\mathrm{T}$ regulatory cells. PLoS One. 2011;6(1):e15868. doi:10.1371 /journal.pone. 0015868 .

57. Iadecola C, Anrather J. The immunology of stroke: from mechanisms to translation. Nat Med. 2011;17(7):796-808. doi:10.1038 /nm.2399.

58. Gonzalez-Moreno EI, Camara-Lemarroy CR, Gonzalez-Gonzalez JG, Gongora-Rivera F. Glycemic variability and acute ischemic stroke: the missing link? Transl Stroke Res. 2014;5(6):638-46. doi:10.1007/s12975-014-0365-7.

59. Suenaga J, Hu X, Pu H, Shi Y, Hassan SH, Xu M, et al. White matter injury and microglia/macrophage polarization are strongly linked with age-related long-term deficits in neurological function after stroke. Exp Neurol. 2015;272:109-19. doi:10.1016/j. expneurol.2015.03.021.

60. Ergul A, Hafez S, Fouda A, Fagan SC. Impact of comorbidities on acute injury and recovery in preclinical stroke research: focus on hypertension and diabetes. Transl Stroke Res. 2016. doi:10.1007 /s12975-016-0464-8. 